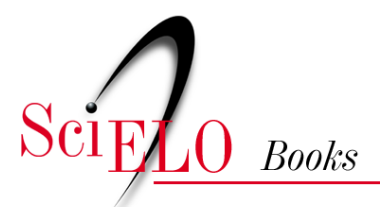

\title{
38. Fritz Koeberle e seus Estudos sobre a Doença de Chagas
}

\author{
Joffre Marcondes de Rezende
}

\section{SciELO Books / SciELO Livros / SciELO Libros}

REZENDE, J. M. Fritz Koeberle e seus Estudos sobre a Doença de Chagas. In: À sombra do plátano: crônicas de história da medicina [online]. São Paulo: Editora Unifesp, 2009, pp. 325-342. História da Medicina series, vol. 2. ISBN 978-85-61673-63-5. https://doi.org/10.7476/9788561673635.0039.

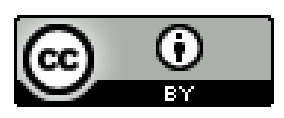

All the contents of this work, except where otherwise noted, is licensed under a Creative Commons Attribution 4.0 International license.

Todo o conteúdo deste trabalho, exceto quando houver ressalva, é publicado sob a licença Creative Commons Atribição 4.0.

Todo el contenido de esta obra, excepto donde se indique lo contrario, está bajo licencia de la licencia Creative Commons Reconocimento 4.0. 


\section{Fritz Koeberle \\ e seus Estudos sobre a Doença de Chagas*}

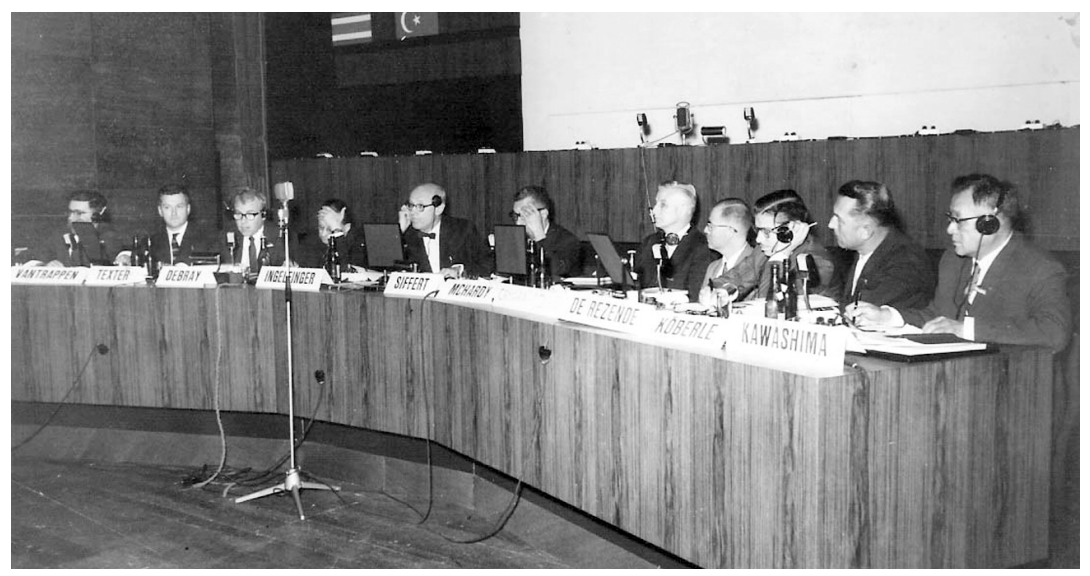

Fritz Koeberle (segundo, da esq. para a dir.) no Simpósio Internacional sobre Acalásia do Esôfago no II Congresso Mundial de Gastroenterologia, maio de I962.

$\mathrm{D}$ iscorrer sobre a pessoa e as realizações do prof. Fritz Koeberle é rememorar um passado recente, que presenciamos e do qual eventualmente participamos.

O prof. Zeferino Vaz, quando organizava o corpo docente da Faculdade de Medicina de Ribeirão Preto da Universidade de São Paulo, tinha, entre os seus objetivos, criar um grande centro de pesquisa e pós-graduação. Ele procurou recrutar professores do mais alto nível, pois, dizia que o mais importante em uma instituição de ensino superior não são os prédios e as instalações, mas os recursos humanos. Recrutou a maior parte dos docentes em nosso país, especialmente na Faculdade de Medicina da usp, porém,

* Apresentado à xviı Reunião Anual de Pesquisa Aplicada em Doença de Chagas e publicado no vol. 35 , supl. in da Revista da Sociedade Brasileira de Medicina Tropical (pp. 25-34, 2002). Os dados biográficos sobre o prof. Koeberle foram, em parte, fornecidos por seu filho, prof. Gottfried Koeberle, a quem agradecemos a colaboração. Nossos agradecimentos são extensivos ao prof. Ulysses Meneghelli, por seu auxílio na obtenção do curriculum vitae do prof. Koeberle. 
quando necessário, buscou no exterior os professores de que necessitava para completar o corpo docente. E, desta maneira, o patologista austríaco Fritz Koeberle foi convidado a dirigir o Departamento de Patologia da recém-inaugurada faculdade.

Koeberle foi informado inicialmente sobre a nova faculdade pelo médico da Embaixada do Brasil em Viena. Houve troca de correspondências e o convite foi formalizado.

$\mathrm{Na}$ sucinta exposição que faremos sobre o prof. Koeberle vamos considerar dois períodos em sua vida: antes e após sua vinda para o Brasil.

\section{Primeiro Período: na Áustria}

Koeberle nasceu em Eishgraben, pequena cidade próxima a Viena, em Io de outubro de ı9ıo, filho de Friedrich e Katharina Koeberle. Toda a sua educação, desde o curso primário, até o superior, deu-se em Viena. Após o curso primário, prestou exame de admissão ao Ginásio Humanístico de Viena, sendo aprovado com distinção. O curso secundário, com oito anos de duração, exigia para a sua conclusão uma dissertação sobre um tema da escolha do aluno. Koeberle optou por um tema ligado à anatomia: $O$ Coração, Com Especial Referência ao dos Animais Vertebrados e do Homem, sendo aprovado com distinção.

No mesmo ano em que terminou o curso secundário ingressou na Universidade de Viena, matriculando-se simultaneamente na Faculdade de Medicina e no curso de Educação Física. Em dezembro de 1934 prestou os exames finais, classificando-se em primeiro lugar, após o que recebeu o título de doutor em medicina (Doctoris Universae Medicine). Contava, então 24 anos de idade.

Durante o curso médico foi estagiário voluntário no Instituto Patológico, além de monitor de pediatria e de oftalmologia. Imediatamente após o seu doutoramento em janeiro de I935, ingressou como assistente voluntário do Instituto Patológico da Universidade de Viena sob a direção do prof. Maresch. Em março do mesmo ano foi nomeado assistente, e em I94 I, professor adjunto do referido instituto, cargo que exerceu até 1946.

O Instituto Patológico da Universidade de Viena mantinha convênio com outros hospitais de Viena para a realização de autópsias e biópsias, o 
que ensejou ao prof. Koeberle a realização em onze anos de cerca de quatro mil autópsias.

Em I939, com a anexação da Áustria pela Alemanha nazista, Koeberle foi forçado a ingressar no serviço militar, inicialmente como tenente-médico do Hospital Central do Exército em Viena e, a partir de março de I940, como patologista do XII Exército, tendo desempenhado esta função na França, Bélgica, Polônia e Rússia. Na campanha da Rússia, em I94 I, foi vítima de malária, depois foi transferido para Münster como patologista do XIII Exército, com a patente de major-médico. Finalmente foi admitido na Universidade de Münster, como livre-docente, cargo que ocupou até o final da guerra.

Durante os anos que serviu ao exército alemão, teve oportunidade, segundo relatou, de praticar numerosas necrópsias de casos de disenteria bacilar, tifo exantemático, febre tifoide, tularemia, malária, além dos numerosos casos de morte por ferimentos bélicos.

A dramática experiência de sua participação no front da Segunda Guerra Mundial o marcou para o resto de sua vida.

Em setembro de 1945 retornou ao Instituto Patológico da Universidade de Viena, onde permaneceu até 3 I de janeiro de I946, quando foi nomeado chefe do Instituto Bacteriológico e Sorológico do Hospital Geral de St. Polten, cidade próxima à Viena, hoje capital da Baixa Áustria. Nesse instituto permaneceu até I953, acumulando a função de chefe do Serviço de Medicina Legal regional. Sob sua direção, o Instituto foi remodelado, tornando-se um dos mais modernos de Baixa Áustria. O número de exames ali realizados elevou-se de 25000 em I 946 para 93000 em I 952.

Em setembro de 1953 requereu licença de três anos para atender ao convite do prof. Zeferino Vaz de organizar e dirigir o Departamento de Patologia da Faculdade de Medicina de Ribeirão Preto. Um dos motivos que pesaram em sua decisão de vir para o Brasil, segundo suas próprias palavras, foi o desejo de dedicar-se à pesquisa, uma vez que em St. Polten tinha uma grande sobrecarga de trabalho de rotina que ocupava a maior parte de seu tempo.

Durante sua carreira docente na Europa, apesar das dificuldades decorrentes da Segunda Guerra Mundial, pôde realizar vários estudos que se materializaram na publicação de dezoito trabalhos científicos e 49 conferências e cursos sobre diferentes temas de patologia, inclusive sobre as doenças epidêmicas que acometeram os exércitos e as populações civis durante a guerra. 
Antes de vir para o Brasil, encontrou-se em Munique com o prof. Henrique Rocha Lima, cientista brasileiro residente na Alemanha e ex-pesquisador do Instituto Oswaldo Cruz. Rocha Lima, autor de pesquisas originais importantes sobre a tripanossomíase americana, despertou em Koeberle o desejo de estudar as doenças inexistentes e desconhecidas na Europa, especialmente a doença de Chagas, que ele, Rocha Lima, considerava um campo fértil para novas pesquisas.

Em sua vida familiar casou-se em 1936 com Elizabeth Koeberle e quando de sua vinda para o Brasil, em I953, o casal tinha quatro filhos (Gottfried, com dezesseis anos; Roland, com quinze anos; Krista, com doze anos, e Erika, com sete anos de idade).

Dois de seus filhos seguiram a carreira universitária, Gottfried na Faculdade de Medicina da Universidade de Campinas, e Roland, como físico, na Universidade de São Carlos, no estado de São Paulo.

\section{Segundo Período: no Brasil}

Em 20 de outubro de 1953 teve início o segundo período da vida do prof. Koeberle quando, recém-chegado com a família ao Brasil, assumiu o cargo de professor contratado de patologia da Faculdade de Medicina de Ribeirão Preto.

"Em Ribeirão Preto", diz ele, “encontrei o que realmente almejava: meios, ambiente, tempo e material abundante para pesquisa nos mais diversos setores da patologia, destacando-se o fascinante problema da moléstia de Chagas”.

E a licença de três anos para sua estada no Brasil transformou-se em sua transferência definitiva com toda a família para o nosso país, sua naturalização como cidadão brasileiro, revalidação de seu diploma de médico e prestação de concurso para professor titular na Faculdade de Medicina de Ribeirão Preto em 1962, cargo que ocupou até sua aposentadoria em I976. Entusiasmado com a oportunidade de estudar uma doença para ele inteiramente nova - a doença de Chagas - procurou antes inteirar-se da literatura médica brasileira existente sobre a mesma. Com seus conhecimentos de latim, cujo estudo integrava o ensino secundário na Áustria, não lhe foi difícil o domínio da língua portuguesa. Dois anos após sua vinda para o Brasil já redigia, ele próprio, os seus artigos escritos em português. 
Megaesôfago, megacólon e doença de Chagas

A questão da possível relação etiológica entre a doença de Chagas e o megaesôfago e megacólon endêmicos no Brasil, que vinha sendo debatida de longa data, tornou-se o núcleo central de suas pesquisas. De um lado, os trabalhos de Amorim e Correa Neto (I932, pp. Ior-I 27), Etzel (I934, pp. 383-395) e Correa Neto e Etzel (I934, pp. 395-420) demonstravam que o megaesôfago e o megacólon eram uma mesma doença, na qual o achado histopatológico mais característico consiste na degeneração do plexo mientérico de Auerbach, encontrada em todo o trato digestivo, e não apenas nos segmentos dilatados.

De outro lado, os dados clínicos, epidemiológicos e sorológicos não deixavam dúvida quanto à relação etiológica entre a doença de Chagas e o megaesôfago e megacólon endêmicos (Etzel, 1939, pp. 238-256; Freitas Jr., I950, pp. 4I I-423; Laranja, Dias e Nóbrega, I948a, pp. 5I-53; Freitas, I947). Restava provar que aquelas lesões eram primitivas e a dilatação secundária e que as mesmas eram produzidas pela infecção por Trypanosoma cruzi.

Tinha-se a ideia, na época, de que seria indispensável o achado do parasito nas paredes do esôfago e do cólon dilatados para a comprovação anatomopatológica da etiologia chagásica. Por esta razão, Koeberle se preocupou inicialmente com o achado de um ninho de amastigotas na parede do megaesôfago. Depois de exaustivas buscas passou a examinar todos os esôfagos de chagásicos autopsiados, até que o encontrou em um caso. Seu primeiro trabalho publicado no Brasil teve a colaboração de seu assistente Estêvão Nador e foi divulgado em novembro de 1955 sob a forma de nota prévia (Koeberle e Nador, I95 5, pp. 643-66I).

Desde sua primeira publicação, Koeberle jamais deixou de fazer referência aos pesquisadores brasileiros que haviam anteriormente descrito as lesões do plexo mientérico no megaesôfago e megacólon endêmicos. O objetivo de suas investigações era demonstrar que tais lesões são produzidas pela doença de Chagas e são responsáveis pelas alterações motoras que levam à dilatação.

Logo compreendeu que o achado do parasito no órgão comprometido não era a questão principal. $O$ fundamental era demonstrar que as formações megálicas são sequelas do processo infeccioso, às quais chamava de "patias" chagásicas, ao contrário de "nósos", a infecção em si. 
"De fato", indaga, "quem procuraria verificar a natureza reumática de um vício cardíaco examinando casos de estenose valvular calcificada? Ou, examinando casos de cicatrização da pele, verificar a natureza estafilocócica da supuração primitiva?" (Idem, p. 652). Em uma conversa que tivemos comparou o mega já estabelecido com uma cidade devastada pela guerra, onde já não se encontram os soldados que promoveram a devastação. $\mathrm{O}$ importante seria estudar quando e como se processa a desnervação, o que poderia ser feito nas autópsias dos chagásicos, com e sem megas, em animais naturalmente infectados, e na infecção experimental em animais de laboratório. Utilizou os três métodos.

Um dos argumentos que se antepunham à etiologia chagásica era de que somente um reduzido número de chagásicos evoluía com alterações megálicas do tubo digestivo. Koeberle teve, então, a ideia de realizar estudo quantitativo dos neurônios do esôfago em indivíduos normais e em chagásicos com e sem megas.

A técnica utilizada consistia na contagem do número de neurônios em segmentos transversais de um anel abrangendo toda a circunferência da víscera, com um milímetro de altura. Os cortes eram realizados em segmentos deste anel, com a espessura de sete micra e contava-se um neurônio em cada sete cortes, tendo em vista a dimensão de um neurônio, a fim de que a mesma célula não fosse contada duas vezes (Koeberle, I962a).

Em um estudo preliminar realizado em quarenta níveis diferentes de três esôfagos normais, ficou evidente que o plexo mientérico contém maior número de neurônios na sua metade inferior, razão pela qual os estudos quantitativos subsequentes foram sempre realizados no terço inferior do esôfago. Em indivíduos normais verificou Koeberle que o número de neurônios decresce com a idade, o que lhe permitiu estabelecer padrões de normalidade para cada faixa etária (Koeberle, Pena e Koeberle, I961, pp. 717-722).

A desnervação encontrada em chagásicos mostrou-se extremamente variável e irregular, independentemente da idade, sendo encontrada mesmo em casos assintomáticos. Nos casos de megaesôfago com dilatação evidente do órgão, os neurônios remanescentes eram escassos, em meio ao processo inflamatório, ou o plexo achava-se substituído por tecido fibroso cicatricial.

Concluiu Koeberle que a evolução da esofagopatia chagásica para um megaesôfago típico só iria ocorrer quando a desnervação atingisse um determinado patamar, que foi estimado em 90\% (Koeberle, I968, pp. 238-260). 
Estudos quantitativos foram igualmente feitos em relação ao cólon, os quais demonstraram que a desnervação não se restringe à parte dilatada, comumente o reto e o cólon sigmoide, mas se estende a todo o cólon, e que o nível crítico de desnervação capaz de promover o aparecimento do megacólon situa-se em torno de $55 \%$ (Idem, ibidem).

Posteriormente, seus colaboradores realizaram estudos quantitativos em todos os segmentos do trato digestivo: estômago (Costa e Alcantara, I965, pp. 667-67I), duodeno (Costa e Alcantara, I966a, pp. I 58-160), intestino delgado (Costa e Alcantara, I966b, pp. 399-400), apêndice cecal (Brandão e Koeberle, I964, pp. 6I I-6I 3) e cólon (Costa e Lima Filho, I964, pp. 2 I I2 I 8), verificando, em todos eles, acentuada redução do número de neurônios em relação aos valores normais.

Em I959 apresentou ao Congresso Internacional sobre a Doença de Chagas, realizado no Rio de Janeiro, seus achados de megaformações em 250 autópsias de chagásicos.

Explicou a dilatação preferencial do esôfago e do cólon distal com base na fisiologia desses segmentos. Ambos necessitam de perfeita coordenação motora para impelir o seu conteúdo semissólido (bolo alimentar no esôfago e bolo fecal no reto) e ambos são providos de um esfíncter em sua extremidade distal, que se torna acalásico, dificultando o trânsito. Os outros segmentos, como o estômago, duodeno, intestino delgado e cólon ascendente têm conteúdo líquido de mais fácil propulsão e por isso raramente apresentam dilatação (Koeberle, I960, pp. 269-277).

Sua tese para professor titular consistiu em um estudo comparativo entre o megaesôfago europeu e o megaesôfago chagásico. Para tanto realizou contagem de neurônios em 33 esôfagos normais, trinta esôfagos de chagásicos, sem dilatação, trinta casos de megaesôfago chagásico e quinze casos de megaesôfago europeu. Concluiu que a patogenia é a mesma, tanto no megaesôfago chagásico quanto no megaesôfago não chagásico (acalásia idiopática) e que "o substrato morfológico consiste na diminuição numérica acentuada dos neurônios do plexo mientérico em toda a extensão do órgão" (Koeberle, Pena e Koeberle, op. cit.).

Koeberle descreveu também, na doença de Chagas, a ocorrência de desnervação em outros órgãos, além do trato digestivo, como a árvore traqueobrônquica (Koeberle, I96ra, pp. 683-690). 
Ramos e Oria (I940, pp. 363-442), em I940, haviam descrito lesões do sistema nervoso autônomo do coração em pacientes com megaesôfago, estabelecendo, assim, um vínculo etiopatogênico desta afecção com a cardiopatia crônica a que está frequentemente associada e cujas alterações eletrocardiográficas são superponíveis às descritas na cardiopatia chagásica crônica (Ramos, I935, pp. I49-I6I).

Era evidente que a cardiopatia encontrada nos pacientes com megaesôfago e megacólon e a cardiopatia chagásica, tão bem descrita por Chagas e Villela (Chagas e Villela, I922, pp. 5-6I) e individualizada por Laranja e outros (Laranja, Dias e Nóbrega, I948b, pp. 473-529), eram uma só e única entidade.

Koeberle estudou em detalhes a desnervação do coração na doença de Chagas, encontrando-a na fase aguda da doença, tal como no trato digestivo. Convenceu-se da importância da desnervação na patogenia da cardiopatia chagásica crônica, considerando-a como o fator principal das alterações morfológicas e funcionais próprias desta cardiopatia, tais como os bloqueios do sistema de condução, as arritmias, a morte súbita por fibrilação ventricular, o aneurisma de ponta e a cardiomegalia encontrada nos casos de descompensação cardíaca (Koeberle, I958, pp. 3 I I-346).

Em sua visão, a cardiopatia chagásica seria, essencialmente, uma cardiopatia neurogênica. Na desnervação encontrada em corações de chagásicos, o parassimpático é mais atingido que o simpático. Tal fato gera um desequilíbrio na regulação neural da frequência e ritmo cardíacos, com maior consumo de oxigênio em condições de esforço e hipersensibilidade do miocárdio às catecolaminas. Os bloqueios do sistema excito-condutor e o aneurisma de ponta seriam explicados como resultado de lesões hipoxêmicas e consequentes microinfartos, independentemente da miocardite. Conforme estudos quantitativos que realizou, a redução média de neurônios encontrada em corações de chagásicos foi de $55 \%$ em relação ao parassimpático e $35 \%$ em relação ao simpático (gânglio estrelado) (Koeberle, I962b, pp. 92-103).

Em alguns de seus trabalhos, Koeberle referiu-se à cardiopatia chagásica crônica como "cardiopatia parassimpaticopriva" (Koeberle, I959, pp. I308-I3 IO). Reconheceu, entretanto, que era mais fácil detectar o parasito no músculo cardíaco do que na parede do trato digestivo. 
Um novo conceito sobre a doença de Chagas

Entusiasmado com os seus achados histopatológicos, Koeberle estabeleceu uma nova visão para a doença de Chagas, conceituando-a como enfermidade do sistema nervoso autônomo. Este conceito abriu novos horizontes para as pesquisas que se seguiram, não apenas sobre a fisiopatologia da doença, como também sobre o participação do sistema nervoso autônomo periférico nos mecanismos de regulação fisiológica dos diferentes órgãos e sistemas.

Nas investigações realizadas em animais de experimentação, utilizando a cepa $\mathrm{Y}$ do Trypanosoma cruzi, verificou Koeberle que o processo degenerativo das células nervosas dos plexos intramurais tem início na fase aguda da enfermidade e com tal intensidade que o levou a formular a frase frequentemente citada de que "o destino do chagásico se decide na fase aguda" (Koeberle, I957, pp. I 55-I80).

Embora conceituando a doença de Chagas como enfermidade do sistema nervoso autônomo por suas manifestações tardias, reconhecia o tropismo do Trypanosoma cruzi para o tecido muscular, tanto de fibras estriadas, como lisas, donde o aparecimento da miocardite na fase aguda da infecção e do parasitismo do tecido muscular estriado e do tecido muscular liso. O plexo mientérico é o mais atingido, exatamente por sua situação topográfica, entre as camadas longitudinal e circular da parede visceral e, assim, em íntimo contato com as células musculares parasitadas que se rompem, liberando os parasitos, com o aparecimento de um processo inflamatório localizado.

Uma vez estabelecida e aceita a etiologia chagásica do megaesôfago e megacólon endêmicos, o passo seguinte seria explicar a patogenia das lesões, o processo de agressão aos neurônios. De pronto afastou o parasitismo dos próprios neurônios ou das células de Schwann, dada a raridade com que estas células albergam o parasito.

A primeira ideia que lhe ocorreu foi da ação de uma possível neurotoxina, que seria liberada pelas formas incompletamente desenvolvidas do parasito e que se desintegravam após a rotura das células musculares parasitadas (Koeberle, I956, pp. 468-475).

A ideia da existência de toxinas provenientes do parasito, independentemente de sua ação sobre as células nervosas, não era original. Chagas, em I 9 16, em seu artigo "Processos Patojenicos da Tripanozomiase Americana" 
já aventara esta possibilidade. São suas as seguintes palavras: "Dos processos patojenicos da tripanozomíase alguns correspondem a localizações específicas do parasito na intimidade dos sistemas orgânicos; outros são atribuíveis à ação de toxinas, cuja existência bem se evidencia em alterações orgânicas e funcionais que permaneceriam, de outro modo, inexplicáveis" (Chagas, 1916, pp. 5-35).

Em I974, em uma discussão sobre a patogênese da doença de Chagas, Koeberle substituiu seu conceito inicial de neurotoxina pelo de uma citotoxina ou citolisina, entendendo-se como tal uma substância de natureza enzimática de ação membranolítica.

\section{Como foram recebidos os trabalhos de Koeberle}

Enquanto os médicos e pesquisadores que trabalhavam em regiões endêmicas da doença de Chagas, convivendo diariamente com os pacientes chagásicos, receberam com entusiasmo as pesquisas do prof. Koeberle, os grandes centros científicos, especialmente do Rio de Janeiro e de São Paulo, receberam com críticas e desconfiança a contribuição de Koeberle.

Até então a doença de Chagas era vista como importante causa de cardiopatia, sem vínculo comprovado com os megas digestivos. Koeberle forneceu o elo que nos faltava na cadeia etiopatogênica entre as lesões neuronais já anteriormente descritas no trato digestivo e a doença de Chagas.

O prof. José Lima Pedreira de Freitas, autor de uma tese sobre a alta positividade da reação sorológica para doença de Chagas em portadores de megaesôfago e megacólon (Freitas, op. cit.), por ocasião do viII Congresso Médico do Triângulo Mineiro e Brasil Central, realizado em Uberaba, de 3 a 8 de setembro de 1956, teceu os seguintes comentários em relação a este fato:

Graças aos trabalhos do prof. Koeberle tivemos o importante argumento anatomopatológico para aceitar definitivamente a etiologia chagásica do megaesôfago e dos outros megas entre nós. Está havendo uma reação muito grande por parte dos nossos pesquisadores em aceitar este fato como estabelecido. Por ocasião da realização dos outros congressos do Triângulo Mineiro e Brasil Central, este assunto foi muito debatido e a etiologia chagásica dos megas aparentemente 
saiu sempre perdendo. Estou certo de que deste ela sairá absolutamente vitoriosa (Freitas, I956, pp. 315-320).

A resistência a que se referia o prof. Pedreira de Freitas tornou-se evidente no I Congresso Internacional sobre a Doença de Chagas, realizado no Rio de Janeiro de 5 a I I de julho de I959. Neste Congresso, o prof. Koeberle apresentou o seu trabalho "Moléstia de Chagas: Enfermidade do Sistema Nervoso", no qual procurou demonstrar que a desnervação encontrada no megaesôfago e no megacólon é parte de um processo universal comum a todos os órgãos, com maiores repercussões no coração e o trato digestivo (Koeberle, I96Ib, pp. 69I-7I6).

Seu trabalho foi alvo de comentários desfavoráveis e, em uma das críticas mais contundentes, foi-lhe dito, com certa ironia, que ele tinha muita imaginação, ao que ele retrucou que, sem imaginação, o máximo que se consegue fazer é uma lista telefônica.

Naquele mesmo congresso foi apresentado o achado de megaesôfago em um macaco autopsiado, que havia sido inoculado dez anos antes com Trypanosoma cruzi. Na verdade, tratava-se do primeiro caso de produção experimental de mega em animal. Seus autores admitiram a etiologia chagásica, porém refutaram a patogênese segundo a qual a dilatação é secundária à lesão do plexo mioentérico.

No I ${ }^{\circ}$ Congresso Internacional de Proctologia, realizado em São Paulo de I I a 17 de setembro de I960, fazia parte do programa uma mesa-redonda sobre megacólon, presidida pelo prof. Alípio Correa Neto, com a participação de Arrigo Raia, Edmundo de Paula Pinto, Joffre Rezende, Fritz Koeberle e M. Aguilera Vischi.

O prof. Koeberle apresentou seu relatório, que se encontra publicado nos Anais daquele congresso (Koeberle, I960). Após a mesa-redonda, fomos todos convidados a assistir uma conferência que não constava do programa, do prof. Edmundo Vasconcelos, sobre a etiologia do megaesôfago e megacólon. Nesta conferência, o ilustre professor de cirurgia procurava demonstrar com documentação histopatológica, que o verdadeiro agente etiológico dos megas era um vírus e não o Trypanosoma cruzi.

Após a conferência, em uma conversa informal de um grupo de congressistas, do qual fazíamos parte, indagaram do prof. Koeberle qual sua opinião 
sobre a teoria exposta pelo conferencista. A resposta foi curta: "Só se o vírus for montado no tripanossoma". O patologista inglês Basil Morson, que se encontrava no grupo, foi consultado sobre a sua opinião. Respondeu com aquele senso de humor britânico que preferia aguardar que os brasileiros chegassem a um entendimento.

Uma vez aceita a etiologia chagásica dos megas, o processo de desnervação do sistema nervoso entérico foi objeto de investigação por outros pesquisadores, que confirmaram os achados de Koeberle, tanto na fase aguda como na fase crônica da doença de Chagas e trouxeram novos aportes à compreensão da patogênese das lesões degenerativas dos plexos intramurais (Tafuri e Brener, I966, pp. 37I-383; Tafuri, Maria e Lopes, I97 I, pp. 76-9I; Andrade e Andrade, I966, pp. 219-224; Okumura, 1967, pp. 192-203).

As discussões passaram a girar em torno do mecanismo de destruição neuronal. As pesquisas realizadas em diferentes centros demonstraram tratar-se de um processo de natureza imunológica, com agressão dos neurônios por células imunocompetentes, processo este ainda não totalmente esclarecido. A teoria de uma neurotoxina ou de uma citolisina foi abandonada.

No plano internacional os trabalhos de Koeberle tiveram maior repercussão. Além de inúmeras conferências que proferiu no exterior, publicou muitos de seus trabalhos em revistas europeias da maior qualificação científica.

No II Congresso Mundial de Gastroenterologia, realizado em Munique, de I3 a I9 de maio de I962, a acalásia do esôfago foi tema de um simpósio, moderado pelo prof. Geraldo Siffert, do Rio de Janeiro, e sob a presidência do prof. Franz J. Ingelfinger, de Boston. Participaram dessa reunião, como convidados, além dos dois já mencionados, G. R. A. Vantrappen, da Bélgica; S. Kawashima, do Japão; G. McHardy e E. C. Texter, dos Estados Unidos; J. R.Trounce, da Inglaterra; C. Debray, da França; J. M. de Rezende, F. Koeberle e L. H. Câmara-Lopes, do Brasil.

Eram línguas oficiais do congresso o alemão, inglês, francês e espanhol, com tradução simultânea. Havíamos combinado, os brasileiros, a utilizar o inglês. Koeberle, no entanto, iniciou sua apresentação em inglês, porém logo abandonou o texto em inglês e fez sua exposição de improviso em alemão, o que causou surpresa aos congressistas que lotavam o auditório, já que Koeberle estava inscrito como brasileiro. Ao final foi aplaudido pelos presentes de pé, fato excepcional em um congresso internacional. 
Até sua aposentadoria, em I976, e na qualidade de professor da Faculdade de Medicina de Ribeirão Preto, o prof. Koeberle desenvolveu intensa atividade científica. Seu curriculum vitae registra 197 conferências, a maioria das quais no exterior, 73 trabalhos publicados e participação em 69 bancas examinadoras. Pertencia a doze sociedades médicas, tendo sido sócio-fundador da Sociedade Brasileira de Medicina Tropical e presidente da Sociedade Brasileira de Patologia, no período de 1966-1968. Era assessor da Fundação de Amparo à Pesquisa do Estado de São Paulo (Fapesp) e da Organização Mundial de Saúde. Foi agraciado com medalha de honra ao mérito pelo governo do Estado de Minas Gerais e pela Faculdade de Medicina de Ribeirão Preto.

"Dinamismo, perseverança, tenacidade e argúcia”, para usar as palavras do prof. Anis Rassi, "foram as tônicas de seu trabalho no Departamento de Patologia da Faculdade de Medicina de Ribeirão Preto" (Rassi, I979, p. I95).

Após sua aposentadoria ainda exerceu atividade docente como professor visitante contratado pela Universidade de Campinas, onde orientou alguns trabalhos de pesquisa.

\section{Koeberle como brasileiro}

Koeberle integrou-se de tal maneira à sua nova pátria que, quando lhe perguntavam sua nacionalidade respondia com orgulho: "Sou brasileiro".

Apreciava a natureza e viajava sempre que se oferecia oportunidade pelo interior para melhor conhecer o nosso país, seu povo e seus costumes. Conheceu o Brasil de norte a sul. Interessou-se pela cultura dos nossos indígenas e foi pessoalmente, acompanhado da esposa e das filhas, visitar a aldeia dos Xavantes, em Mato Grosso, e dos Carajás, na ilha do Bananal.

Tivemos ocasião de acompanhá-lo em algumas de suas incursões pelo interior de Minas Gerais e Goiás. Entusiasmava-se com a riqueza potencial do Brasil e com os nossos recursos naturais. Quando conheceu as fontes hidrotermais de Caldas Novas, ao tempo em que a nascente do rio Quente ficava no meio do mato e ali se chegava por uma estrada de terra, fez o seguinte comentário: "Se fosse na Europa teria de se pagar caro para conhecer esta maravilha”. Previu que ali seria um grande centro turístico, o que realmente se concretizou alguns anos depois. 
Certa vez desejou possuir uma roda de carro de boi, autêntica, para dela fazer uma mesa para o seu jardim. Conseguimos a roda, que lhe demos de presente, o que muito o alegrou. Infelizmente, esta mesa lhe foi roubada em sua ausência.

Mais de uma vez referiu-se à hospitalidade do brasileiro e à maneira cordial com que os nossos "caboclos", como os chamava, tratam as pessoas desconhecidas e se mostram sempre prontos a colaborar diante de qualquer dificuldade.

Por vezes criticava alguns hábitos que observava no Brasil, como o desperdício de alimentos. Ao ver-me retirando a camada superficial de alguns pedaços de queijo em uma lanchonete, perguntou-me o que seria feito com aquilo. Respondi-lhe que seria jogado fora. Inconformado, comeu todas aquelas sobras, dizendo: "Vocês nunca tiveram uma guerra!".

Viajava muito para o exterior a fim de atender convites ou por conta própria. À primeira vista, Koeberle dava a impressão de ser uma pessoa autoritária, de uma franqueza rude e por vezes agressiva. Conhecendo-o mais de perto e por mais tempo, via-se que por trás daquela aparência havia um ser humano sensível, sincero e prestativo.

\section{Um amigo de Goiás}

Inúmeras vezes, Koeberle foi a Goiânia para proferir conferências, participar de cursos e congressos, ou acompanhando visitantes ilustres de outros países.

Interessava-se e valorizava sobremaneira os estudos de natureza clínica sobre a doença de Chagas, notadamente em relação à fase aguda, à cardiopatia e ao megaesôfago e megacólon, realizados pelos "bugres de Goiás", como ele nos chamava, troçando, a mim e ao colega Anis Rassi.

Foi um colaborador permanente da Faculdade de Medicina da Universidade Federal de Goiás e seu laboratório em Ribeirão Preto sempre esteve à disposição dos docentes da referida faculdade para a realização de exames histopatológicos em trabalhos de pesquisa sobre a doença de Chagas. Participou de mais de um trabalho feito em colaboração.

Prestigiou a Revista Goiana de Medicina, nela publicando vários artigos de sua autoria ou de seus colaboradores, a partir de 1956 , inclusive 


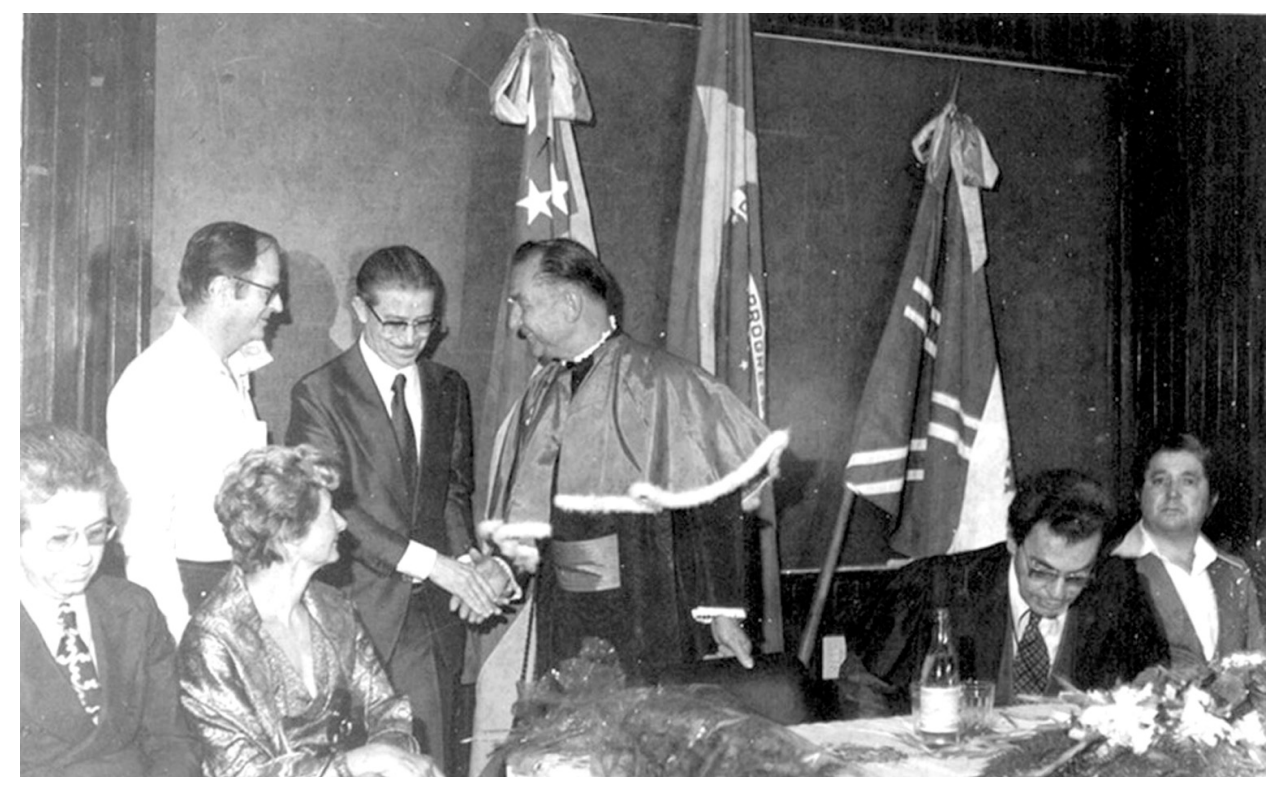

Koeberle recebe o título de professor honoris causa da Universidade Federal de Goiás.

sua tese para professor titular. $\mathrm{O}$ apoio que emprestou à citada revista muito contribuiu para o prestígio da mesma e sua projeção no cenário internacional.

Em reconhecimento aos seus méritos de pesquisador, à sua contribuição à medicina brasileira e sua permanente colaboração com os pesquisadores goianos, a Universidade Federal de Goiás, por iniciativa conjunta da Faculdade de Medicina e do Instituto de Medicina Tropical, conferiu-lhe o título de professor honoris causa em 9 de novembro de I978. Na foto acima veem-se, sentados da esquerda para a direita, Anis Rassi, Elizabeth Koeberle, José Cruciano de Araujo e Joaquim Caetano de Almeida; de pé, Jarbas Doles, Joffre Marcondes de Rezende e o homenageado, Fritz Koeberle. $\mathrm{Na}$ ocasião, o prof. Koeberle foi saudado pelo prof. Anis Rassi em nome da universidade.

Assim como Carlos Chagas, Koeberle faleceu subitamente de infarto agudo do miocárdio, em sua residência, em Americana, no estado de São Paulo, em 20 de fevereiro de I983, no mesmo dia em que se instalava no Rio de Janeiro, o xIx Congresso da Sociedade Brasileira de Medicina Tropical. Contava, então, 72 anos de idade. 
Deixou seu nome inscrito em caráter permanente na galeria dos grandes vultos da medicina brasileira por suas pesquisas sobre a doença de Chagas. Apesar de estrangeiro, tornou-se brasileiro, segundo as nossas leis, e de coração. Amou o Brasil tanto quanto os aqui nascidos. Dedicou-se de corpo e alma ao estudo de uma doença que é patrimônio científico do nosso país.

A sua contribuição, as suas ideias, foram alvo de críticas e incompreensões e certamente tiveram suas falhas que foram corrigidas pelos pesquisadores que o sucederam. Assim progride a ciência, pois nenhum trabalho humano é perfeito.

O que é inegável é que a sua contribuição constitui um marco na história da doença de Chagas.

\section{Referências Bibliográficas}

Amorim, M. \& Correa Neto, A. "Histopathologia e Pathogenese do Megaesophago e do Megarecto: Considerações em torno de um Caso de Mal e Engasgo". Anais da Faculdade de Medicina da Universidade de São Paulo, 8, pp. IOI-I27, I932.

Andrade, S. G. \& Andrade, Z. A. "Doença de Chagas e Alterações Neuronais no Plexo de Auerbach: Estudo Experimental em Camundongos”. Revista do Instituto de Medicina Tropical de São Paulo, 8, pp. 219-224, I966.

Brandẽo, H. J. S. \& Koeberle, F. “O Apêndice Cecal na Moléstia de Chagas: Estudo Quantitativo dos Neurônios do Plexo Mientérico”. Revista Brasileira de Medicina, 2I, pp. 6II-6I3, I964.

Chagas, C. "Processos Patojenicos da Tripanozomiase Americana". Memórias do Instituto Oswaldo Cruz, 8, pp. 5-35, I9I6.

Chagas, C. \& Villela, E. “Forma Cardíaca de Trypanosomiase Americana”. Memórias do Instituto Oswaldo Cruz, I4, pp. 5-6I, I922.

Correa Neto, A. \& Etzel, E. "Le megaesophage et le megacôlon devant la theorie de l'Achalasie. Étude clinique et anatomo-pathologique”. Revue Sud-Américaine de Médicine et de Chirurgie, 5 (7), pp. 395-420, I934.

Costa, R. de B. \& Alcantara, F. G. de. “Duodenopatia Chagásica”. Revista Brasileira de Medicina, 23, pp. I 58-160, I966а. . "Gastropatia Chagásica Crônica”. Revista Brasileira de Medicina, 22, pp. 667-67I, I965. 
Plexos submucoso e mientérico do íleo humano na moléstia de Chagas.

Revista Brasileira de Medicina 23: 399-400, 1966b.

Costa, R. de B. \& Lima Filho, E. C. de. "Plexos Submucoso e Mientérico do Cólon Humano na Moléstia de Chagas”. Revista do Instituto de Medicina Tropical de São Paulo, 6, pp. 21 I-2 I 8, I964.

Etzel, E. “El Megaesófago en el Brasil: Estudio de 626 casos”. Boletin de la Sociedad de Cirugia de Buenos Aires, 238-256, 1939.

. "Neuropatologia do Megaesofago e do Megacolo: Estudo de 5 Casos”. Anais da Faculdade de Medicina da Universidade de São Paulo, Io, pp. 383-395, I934.

Freitas, J. L. P. de. "Comentário aos Trabalhos Apresentados ao 8 Congresso Médico do Triângulo Mineiro e Brasil Central sobre o Tema: Estado Atual da Doença de Chagas em Goiás". Revista Goiana de Medicina, 2, pp. 31 5-320, I956.

. Contribuição para o Estudo do Diagnóstico da Moléstia de Chagas por Processos de Laboratório. Tese da Faculdade de Medicina da USP, I947.

Freitas JR., S. V. “Megacolo e Megaesôfago no Brasil Central”. Resenha Clínica Científica, I9, pp. 4II-423, I950.

Guimarães, J. F. \& Miranda, A. "Megaesôfago em Macaco Rhesus com io Anos de Infecção Chagásica”. Anais do Congresso Internacional sobre Doença de Chagas (I959), 2, pp. 683-690, I96I.

Ingelfinger, F. J. \& Siffert, G. (eds.) “Aktuelle Probleme der Achalasie des Oesophagus”. Anais do II Congresso Mundial de Gastroenterologia, vol. I, München, I962.

Koeberle, F. "Bronquiectasia Chagásica”. Anais do Congresso Internacional sobre Doença de Chagas (1959), 2, pp. 683-690, I96ra.

. "Cardiopatia Chagásica”. O Hospital, 53, pp. 3 I I-346, I958.

. "Cardiopatia Parassimpaticopriva”. Munchener medizinische Wochenschrift, IOI, pp. I308-I310, I959.

. "Moléstia de Chagas: Enfermidade do Sistema Nervoso". Anais do Congresso Internacional sobre Doença de Chagas (I959), 2, pp. 69I-7I6, I96Ib.

"Pathologic Anatomy of Enteromegaly in Chagas Disease". Bockus Alumni International Society of Gastroenterology: Proceedings $2^{\text {nd }}$ Biennal Meeting, Rio de Janeiro, I962b.

. "Patogenia da Moléstia de Chagas". In Cançado, J. R. Doença de Chagas. Belo Horizonte, Imprensa Oficial, I968, pp. 238-260.

"Patogenia da Moléstia de Chagas: Estudo dos Órgãos Musculares Ôcos".

Revista Goiana de Medicina, 3, pp. I 55-I80, I957. 
.Patologia do Megacolo Adquirido". Anais do Iํㅡㄹ Congresso Latinoamericano, $2^{\circ}$ Internacional e Io ${ }^{\circ}$ Brasileiro de Proctologia, I, pp. 269-277, I960. . Patogenia do Megaesôfago Brasileiro e Europeu. Tese para o concurso da cátedra de Patologia da Faculdade de Medicina de Ribeirão Preto da UsP, I962a. . "Uber das Neurotoxin des Trypanosoma cruzi". Zentralblatt fur Pathologie, 95 , pp. 468-475, I956.

Koeberle, F. \& Nador, E. "Etiologia e Patogenia do Megaesôfago no Brasil”. Revista Paulista de Medicina, 47, pp. 643-66I, I955.

Koeberle, G.; Penha, D. \& Koeberle, F. “Aperistalse Chagásica do Esôfago”. Anais do Congresso Internacional sobre Doença de Chagas (1959), 2, pp. 7I7-722, I96I.

Laranja, F. S.; Dias, E. \& Nóbrega, G. "Estudo Eletrocardiográfico de 8I Casos de Megaesôfago". Brasil Médico, 62(8-9), pp. 51-53, I948a. . "Clínica e Terapêutica da Doença de Chagas". Memórias do Instituto Oswaldo Cruz, 46, pp. 473-529, I948b.

Okumura, M. “Contribuição para o Estudo das Lesões dos Neurônios do Plexo Mientérico do Colo na Moléstia de Chagas Experimental no Camundongo Branco (Mus musculus)". Revista do Hospital das Clínicas da Faculdade de Medicina da Universidade de São Paulo, 22, pp. 192-203, I967.

Ramos, J. "Electrocardiographie chez les malades atteints de megaesophage et megacolon”. Folia Clinica et Biologica, 7, pp. I49-I6I, I935.

Ramos, J. \& Oria, J. "Clínica e Histopatologia do Coração em Portadores de Megaesôfago e Megacólon”. Arquivos de Cirurgia Clínica e Experimental, 4, pp. 363-442, I940.

Rassi, A. "Noticiário”. Revista Goiana de Medicina, vol. 25, p. I95, I979.

TAfuri, W. L. \& Brener, Z. "Lesões do Sistema Nervoso Autônomo do Camundongo Albino na Tripanosomíase Experimental na Fase Aguda”. O Hospital, 69, pp. 37I-383, I966.

Tafuri, W. L.; Maria, T. A. \& Lopes, E. R. "Lesões do Plexo Mientérico do Esôfago, do Jejuno e do Colo de Chagásicos Crônicos: Estudo ao Microscópio Eletrônico”. Revista do Instituto de Medicina Tropical de São Paulo, I3, pp. 76-9I, I97I. 